1. Metal Music Studies

2. Volume 4 Number 1

3. (c) 2018 Intellect Ltd Article. English language. doi: 10.1386/mms.4.1.0_1

4.

5.

6.

\title{
Decay as a black metal
}

\section{symbol}

\section{ABSTRACT}

This article intends to dissect black metal's interestingly twisted relationship with decay. A deep study encompassing symbols of atrophy, with the eventual intention of observing and analysing them through a kaleidoscope of philosophical thought, influenced by, amongst others, the musings of Bataille, Kant and Nietzsche. Issues appearing in both the realand the metaphorical will be placed under inspection, and a suitably blackened light will be shone towards the extent of how black metal exists and thrives in the organic collapse of matter and sound. There will be discussions on how black metal has itself become attuned to decay and how the two processes feed off each other, exist in harmonic conjunction and on rare occasions, oppose the other's being. How black metal has metastasized with atrophy. Here we shall see two forces inexplicably intertwined, the numerous links given exposure and attempted understanding in the realm of black metal theory.

43.

44.

45.

46.

Walking through genocidal remnants

With a hate-fuelled heart

Stabbing even at the tears of withering corpses,

Will there even be a word known as death anymore,

When left is nothing to kill? ${ }^{1}$ 
The objective of this article is to isolate and analyse themes of decay within 1 . black metal music and culture. It will become apparent that examples of decay 2 . permeate the subculture and its output and that these examples are multifac- 3 . eted in their presentation and meaning. For example, the basic descriptive, 4. literal interpretations of decomposition, as seen in the top part of the above 5 . extract, to more complex, interwoven ideas that derive from such a concept. 6 . In the lyrics, the description of bodily decay, from the perspective of a surviv- 7 . ing victor on a battlefield, quickly turns into a philosophical question as to the 8 . nature of being in a state where there are no longer living things. The passage 9 . asks if death ceases being corruptive, when life is no longer a phenomenon 10 . itself. This is a perfect example of how this article will progress. There are three 11. main perspectives of decay in black metal that are analysed within; 'decay 12 . within physical sound', 'decay as a lyrical theme' and 'decay as transgression 13. from the self' - each of these will be further sub-categorized as required, for 14 . clarity and depth. Following this, there will be some alternative perspectives 15 . grouped that do not necessarily fit into the main categories.

In this genre, decay can form complex relationships between the narrator and various subjects. Each significant in its own way, purposefully espousing hidden meanings behind black metal; the raison d'etre of its putrid existence. The suggestion of decay occurs both within and beyond the lyrics, entwined into the music itself, emphatically deriding the futility of man's struggle in the face of this overwhelming putrefaction. Messages of decay symbolize a flowing force echoing the disgust and abjection central to the tenets of the scene. This article will attempt to dissect blâck metal's relationship with decay and place it in the spotlight in terms (6f) philosophical thought with particular reference to the work of 'Black Metal Theory' and implications on the wider spectrum of the entire subculture.

Black metal theory, the contextual blueprint for such study, provides a number of entry points into an analysis of decay. This strain of theory takes a number of themes and looks at them through a 'blackened' lens, being that of a terminal state of finality as an 'un-life world' dies. This un-life world - a world that exists without possessing the qualities for living well within it (Fox 2009: 7). Consequently, all inhabitants of this un-life world exist in perpetual suffering. Black metal theory deftly intersects black metal, philosophy and academic diseourse (Wilson 2010: 35), offering equal favour to all. 'Not black metal. Not theory. Not not black metal. Not not theory' as stated by Masciandaro (2010), implying that this discipline's objectives are an effective double negation, therefore an affirmation of black metal and theory. Black metal revels in its own mystique and existence outside of understanding, and theory 'blackens' it adding a critical gaze, changing its scope towards an allencompassing negativity. This article concentrates on atrophy exhibited within the genre and wider subculture, using black metal theory as a starting point.

\section{A brief overview of black metal and decay}

Arnett, in his book, Metal Heads: Heavy Metal Music and Adolescent Alienation, provides case studies that conclude that level of devotion to the heavy metal subculture is indicative of a youth's discordant relationship with society (Arnett 1996). Regrettably, black metal is mainly absent from this research piece, due to the time frame and the almost complete lack of black metal influence in the United States at the point. However, the general consensus, if assumed to be accurate, provides evidence that heavy metal fan culture corresponds

$$
\begin{aligned}
& 2 . \\
& 3 . \\
& 4 . \\
& 5 . \\
& 6 . \\
& 7 . \\
& 8 . \\
& 9 . \\
& 10 . \\
& 11 . \\
& 12 . \\
& 13 . \\
& 14 . \\
& 15 . \\
& 16 . \\
& 17 .
\end{aligned}
$$


1. to previous work on subcultural relationships. Higher levels of alienation and

2. estrangement from society may lead to further and deeper submersion in

3. the music and adoption of cultural tropes and styles, as a specific rejection

4. of societal dominant culture (Arnett 1996). This idea can be likened to decay,

5. in that the amount that the individual's relationship with mainstream society

6. is 'decayed', the level of their devotion rises, filling the schism. Black metal's

7. appeal is unlikely to garner the same level of attention as the wider heavy

8. metal subculture; hence the numerous isolated microcosmic scenes spread

9. throughout the world (Harris 2000). Scenes that achieve their notoriety in part

10. due to the globalizing effects of the Internet and the ease of transmission of

11. music and cultural output (Kristiansen 2011: 34) leading to larger distribu-

12. tion networks and cross-pollination of scenes (Ekeroth 2008: 48). All iterations

13. will look at decay at some point, as a physical concept, a horror aesthetic or a

14. result of their influences.

15. Kahn-Harris' work, Extreme Metal: Culture on the Edge (2007), offers a series

16. of ethnographic studies into the subculture, which are far more descriptive

17. than Arnett on the theme of countering the connection between alienation

18. and consumption in a culture where even 'buying a CD means to become

19. "involved" in the scene' by 'causing some sort of effect within it' (Harris 2007:

20. 22). He surmises that it is difficult to make distinctions between 'active' and

21. 'passive' scene membership (Harris 2007: 22). Comparing this to a state of

22. decomposition, within the scene - when even the briefest of peripheral contact

23. with the subculture can be effective in altering the landscape, as opposed to

24. this ability being exclusively available to central figures, decay moves outwards

25. infecting more, drawing from the peripheries to feed the sickness at the

26. epicentre. Subcultural capital, or the currency gained from the act of attaining

27. subcultural status provides individuals with inexplicable value that displays

28. their prominence over other members. This can result in levels of influence on

29. the scene as a whole. The black metal subculture subverts this and engages in

30. the pursuit of 'transgressive subcultural capital' (Harris 2007: 127). Subcultural

31. capital obtained through transgression becomes the macabre one-upmanship

32. that defines the black metal culture's attitudes, particularly during the notori-

33. ous 'Second Wave'.

34. When an object is patrefying, it is being consumed at an exponential rate.

35. Decay is not an immediate process, but long and slow. Decay can be observed

36. from the beginning to completion, upon which the victim is fully destroyed

37. (Negarastani 2010). It is here that the most nihilistic and destructive strains

38. of black metal find a spiritual home, observing, condemning and encouraging

39. different forms of decay. This will be covered in the hope of expanding upon

40. the meaning of decay as a symbol of near-infinite power within the subcul-

41. ture. It must be stressed that this article will only focus on destructiveness as

42. a slow, systemic process. The immediate annihilation that runs concurrently in

43. the genre is outside of the target of this article.

44.

45.

46.

47.

48.

49.

50.

51.

52.

\section{Decay embedded within physical sound}

Before looking into the decay observable in the lyrics of black metal, there is also the symbolic decay that takes place in the commonly 'lo-fi' recordings and the soundscape. The following are four ways that the recordings provide this putrefaction. Primarily, one must consider the importance of the music itself. The black metal sound is as pivotal to the concept of decay as any metaphorical categories that can be drawn from deeper attention. As the 
ultimate counter to the overproduced music created for mass consumption - 1 . the outwardly poor recording quality of the subculture's sonic output is both 2 . a construct and circumstantial. Circumstantial in that the recording studios 3 . would not allow the bands in to record their material, refusing to acknowledge 4 . the artistic content of black metal (Ekeroth 2008: 266). Henceforth, the earli- 5. est black metal recordings were made as cheaply as possible, in the homes 6 . of the musicians, on amateurish recording material (very often a cassette 7 . recorder in the centre of the rehearsal room) on a very limited budget. This 8 . lack of a budget led to the second revelation of the black metal recordings, 9 . since these early demos were recorded to cassette, and reproduction was 10 . a case of using a hi-fi system to record onto another tape (either supplied 11. by the consumer or from a stock of cassettes). The quality of the recording 12 . would diminish with each generation of reproduction. As such, one original 13. rehearsal tape used repeatedly would eventually collapse - enveloping the 14 . initial recording in muddying amounts of fuzz and distortion. Thus, the music 15. itself would effectively rot from a state of relative fullness and clarity, towards 16 . disparity and confusion (Russo 2010). In this wayej can be argued that black 17. metal forges towards its own completion, long after the recording is finalized. 18. A Kantian 'striving for completeness' comes to mind, but also Husserl, in that 19. such completeness of knowledge is unattainable, and striving for it can there- 20 . fore never be relinquished, thus the journey is self-defeating (McGuirck 2014: 21. 7). Here decay becomes a charge for completeness. Exponential reduction as a 22. process, in order to make oneself whole, in black metal terms, forging a path 23. towards increased disparity.

Black metal revels in the abject. Kahn-Harris writes: "The abject is that 25 . which is formless, disgusting terrifying and threatening. [...] The abject 26. has to be removed from orderly society and/or destroyed' (2007: 29). Black 27. metal, in self-identification as the abject, signals that it wishes to be outside 28 . of society, waging war on it and begging to be destroyed by inciting hatred 29 . among Christians (amongst others). The abject decay; the formless, disgust- 30. ing collapse, bring to mind a subculture that brings rot to polite society while 31 . simultaneously holding up a mirror to it, that is itself, in the process of atro- 32. phy. The constructed part of the black metal sonic template was meant to 33 . stand against the ever increasingly complex guitar tones that musicians in 34 . other genres, particularly the burgeoning death metal scene, would adopt. 35. Effects pedals would increase in number and function and guitarists espe- 36. cially would have'signature' custom models of their favourite instruments and 37 . amplifiers for both their own personal use and to sell to other musicians who 38 . wanted to approximate/reproduce their signature sound. In reaction, black 39. metal bands would use as minimalist of a set-up that they could be satisfied 40 . with, introducing long-standing elements of primitivism to their work. Many 41. early demos were made by plugging a guitar directly into an amp selecting the 42 . distorted channel, turning it to 10 and then 'dialling in' the following settings: 43. bass: 0-1, middle: 0-1, treble: 8-9 (Moynihan and Søderlind 2003). This result- 44. ing tone is high-pitched, cutting through all other instruments, whereas in 45 . other genres, the guitars would work in tandem with the rest of the instru- 46 . ments, all operating on roughly the same tonal pitch and frequency. It empha- 47. sizes the distorted nature as the sound constantly threatens to self-destruct, 48 . the natural 'buzzing' from the overdriven guitar adds to the ominous atmos- 49 . phere in the finished mix. Along with this, the bands would often further give 50 . presence to the lack of bass or 'low end' in their sound by playing high-pitched 51 . tritone riffs. In direct contrast to the power chords used by death metal bands, 52 . 
1. black metallers chose to strike full chords. Thus creating a disorientating

2. atmosphere, as the signal through the amplifier would be muddied by what

3. the listener would interpret as missing notes.

4. Thirdly, due to the DIY (Do-It-Yourself) attitudes of members like Oystein

5. Aarseth of Mayhem who wished to keep their scene to themselves, they would

6. produce and print their own cassette covers. Crudely hand-drawn logos and

7. pictures of rotting corpses or Satan himself, or photos of forests at night (to

8. name but two recurring themes) photocopied repeatedly until the quality of

9. these too would diminish. The fourth and final instance of decay in the record-

10. ings came from photographs taken of band members. The pictures would very

11. often be blurred and of very poor quality - concealing the musicians' iden-

12. tity as they stood clad in black, faces adorned with corpse paint standing in

13. graveyards or in forests. The image of death featured everywhere in this music.

14. The artists would do everything they could to appear dead and sound hell-

15. ish and demonic. These early black metal demos can arguably, at least to the

16. musicians and their dedicated fans, be a close approximation to what death

17. itself sounds like (Moynihan and Søderlind 2003). Furthermore, looking at the

18. soundscape holistically, analysing intentional use of lo-fi recording methods,

19. stripped song structures, adding wild amounts of distortion - all construct a

20. template that wallows in decay as musical atrophy. Such decay can be seen as

21. a negation of the completeness of music, resulting in music that rots, eating

22. away at concepts of melody and the basic musical form. Black metal leaves

23. us wondering about the difference between music and noise, breaking down

24. the metaphysical barrier that separates them (Tharcker 2014). Decay in this

25. way is transgression against not only the pereeived generality of music, but

26. against society itself. When Erik Danielsson of Watain, for instance, combines

27. his transmission of pain with such hellish, atrophied notes, a soundtrack to

28. suffering emerges and ruptures, spreading to those who choose to consume

29. it. Consequently, listeners are encouraged to share in that transcendence as a

30. result.

31.

32.

33.

34.

35.

36.

37.

38.

39.

40.

41.

42.

43.

44.

45.

46.

47.

48.

49.

50.

51.

52.

\section{Decay as a lyrical theme}

To accurately place lyrical decay in context, it will be presented in three distinct sub-categories: physical decay, societal decay and effectual decay. Physical and societal decays are merely observed by the artists and then regurgitated and explored in the music's lyrics, whereas 'effectual decay' we will see as being the concept of wilful decay on the outside world intended by the artists themselves, in other words, where the artists seek to proffer or encourage decay and destructiveness (Russo 2010).

\section{Physical decay}

Hot tears spill

From the sky's open scam.

An ash breeze pours

From our pure mouths

Partake of this dying fruit ${ }^{2}$

I will lay down my bones among the rocks and the roots of the deepest

hollow next to the streambed

The quiet hum of the earth's dreaming is my new song

When I awake, the world will be born anew ${ }^{3}$ 
3. Wolves in the Throne Room (2007).

4. Mayhem (1995).
While black metal artists are outwardly atavistic and delight in primitivism, 1 . selecting rural, misanthropic existences over urban living, such as the farm 2 . homestead owned by the Weaver brothers, who make up the band Wolves in 3 . the Throne Room. Even if the actuality of this is difficult for many, the fantasy 4 . still remains. This lust for a primitive existence can manifest in observing urban 5 . decay, commenting on the soullessness of the concrete jungle, highlight- 6 . ing the struggle against the 'dying fruit', as in the above extract from Fauna's 7 . 'Rain'. Quite often, bands will contrast this with rural decay in forest settings, 8 . either as a direct comparison or as a statement that suggests that in the city, 9 . decay consumes and destroys - however in the forests, decay contributes to 10 . forming new life (Shakespeare 2012). This dichotomy - decay as an expres- 11. sion of ultimate and finite destruction versus decay as an ingredient in contin- 12 . uing life exemplifies the view of destructiveness in the subculture. Whereas 13. decay is destructive in the weak urban landscape, it reveals a creative face in 14 . the stronger rural wilderness. The above extract from Wolves allows listeners 15. to realize that the forests however decayed or dilapidated will spring forth 16 . new life. 'When I awake...' can be interpreted as the continuation of the narra- 17. tor's life force transposed into a new form, the identity of which, he is uncer- 18. tain. This amalgamation of life forces presented and transformed across the 19. gamut of flora and fauna shows that life is not individualistic, but a universal 20 . collection of equivalent souls that can change their outward form, but inter- 21 . nally are never changing. By synchronižng himself with the natural world, he 22 . becomes one with it. Breaking down existing barriers between continuous and 23 . discontinuous life. Once the narrator is born a new, that dividing line between 24 . continuousness and discontinuousness is lost forever. The very act places him 25 . outside of mortal humanity, symbotic of the desire to return to the Earth and 26. pare oneself from society. Therefore decay, in itself, is once again contradictory, 27. both illusory and vital for continuance of nature, dependent on context and/ 28 . or location.

Comparing the wo lyrieal extracts displays the diverging attitudes towards 30 . decomposition. Onthe one hand, Fauna have declared themselves differenti- 31. ated, beings 'of pure mouths' who are outwardly suffering amongst the remains 32 . of the natural world, the 'ash breeze' being symbolic of the lack of nutrition, 33. consumable from this world. In stark contrast to this, Wolves equate them- 34 . selves with the natural world and willingly submit to it. Fauna effectually suffer 35. from man's domination of nature, whereas Wolves, in their submission, do not. 36.

The physical decay elements also applies to bodily integrity, the most 37. famous example proving this is the cover of Mayhem's bootleg Dawn of the 38 . Black Hearts, ${ }^{4}$ which features Aarseth's photograph of Per Yngve Ohlin's 39. (aka 'Dead', the band's tragic vocalist) bloodied corpse. With the advent of 40. corpse paint, it is clear that the wearer wished to appear dead and rotting. 41. Re-imagining the body as perpetually rotting from birth, as opposed to the 42 . more common concept: 'from the moment we are born; we are dying' (Russo 43. 2010). Through references to the physical decay of the human body, the black 44 . metallers propose that humans are essentially all equal. Without personality, 45 . without knowledge, without a soul, we are the same. It is the components 46 . that are drawn out upon death and decay that constitute our differences. We 47. choose our own weaknesses. Weaknesses such as religion, consumerism, 48. humanity, etc., these differences are illusory, and black metal is the hammer 49 . picking away at these illusions, similarly as to how the corpse state is a fleet- 50 . ing one and eventually will return to the earth after decomposition has taken 51. possession. 


\section{Societal decay}

2.

3.

4.

5.

6.

7.

8.

9.

10.

11.

12.

13.

14.

15.

16.

17.

18.

19.

20.

21.

22.

23.

24.

25.

26.

27.

28.

29.

30.

31.

32.

33.

34.

35.

36.

37.

38.

39.

40.

41.

42.

43.

44.

45.

46.

47.

48.

49.

50.

51.

52. is left alone.
Drifting In the air above a cold lake is a soul

From an early better age

Grasping for a mystic thought In vain [...] but who's to know

Further on lies eternal search for theories to lift the gate

Only locks are made stronger and more keys lost as logic fades

In the pool of dreams the water darkens for the soul that's tired of search

As years pass by the aura drops as less and less feelings touch

Stupidity has won too much the hopeless soul keeps mating ${ }^{5}$

Considering societal decay through black metal themes, one may believe that suddenly the genre begins to engage with the political world; however, the truth is far more complex. Although smaller politically active iterations exist, they are incredibly niche. It is still rare for black metal to outwardly procure political themes in their lyrics, despite the often overemphasized National Socialist Black Metal subgenre. Aarseth, a communist, decided that in mastering this genre, he would stand as far apart from the 'socially conscious' death metal scene, as he possibly could. Black metal allows for all the youths' negativity to shine through - death, decay, darkness, hatred and gore constitute a larger mass of the overall lyrical content. Mainstream politic for the most part

In black metal, it is common to find the theme of the loss of the enhanced ability of primitive man. Varg Vikernes (of Burzum, aka Count Grishnakh) when speaking about the song 'Feeble Screams from Forests Unknown', he maintains that this is the ultimate Burzum) song, in which the project's message is at its zenith, the remainder of his material has been weaker interpretations of the same message. ${ }^{6}$ Vikernessuggests that society as a whole is decaying and we are getting further from our roots. Unable to understand the mystic thought of our pagan ancestry, and ho longer do we have the keys to lift the cosmic gates to ethereal knowledge,

Furthermore, each generationdecays and gets progressively worse. This message is reiterated in many places. The cover of Ulver's Nattens Madrigal: Aatte Hymne til Ulven i Manden (Madrigal of the Night: 8 Hymns for the Wolf in Man') features Q shadow of a wolf howling at the moon. This wolf is dead-eyed and hungry (Richardson 2012), the silhouetted tree behind it appears twisted, gnarled and ugly, enhancing the intimidating nature of the image. Humanity has evolved so far from our natural form that we have made symbolic enemies of the natural forces. What should be so familiar to us is now strange and foreboding. We have evolved into an alien race unfit for the environment - where our ancestors would cooperate and work the land; now we use machinery and pesticides to achieve our ends, altering the land to suit our wishes. Now, the environment is both intense and ominous. It is also seemingly in direct competition with humanity for control of this planet. The black metal subculture hopes the natural world will emerge triumphant.

\section{Effectual decay}

So I will wait, sit on my throne,

Gazing at the sky, in search of answers

And time will fade out, slowly over my corpse.

Day after day, I rot

Expecting light that will bless me for the rest of eternity.

\author{
5. Burzum (1992). \\ 6. Aites and Ewell (2009).
}


7. Celestia (2008).

8. Mayhem (1987).
I will tend to forget the taste of all the seeds I had to taste ${ }^{7} \quad 1$.

Bleed down to the fucking core 2.

You're going down for fucking more 3 .

Screw your slimy guts 4.

Driving me fucking nuts! 5.

Chainsaw in my bleeding hands 6.

As I start to cut you in two

Your guts are steaming out 8 .

And I just love the sight! 9.

$\begin{array}{ll}\text { Maggots crawling in her cunt } & 10 .\end{array}$

I just love to lick that shit 11.

Bury you in a slimy grave 12.

$\begin{array}{ll}\text { You will rot forever there! } & 13 .\end{array}$

14.

The adjective 'effectual' when placed ahead of decay will be used here to 15 . describe decomposition that is encouraged and/or celebrated by the musicians 16 . of the black metal subculture, either physical or societal. It can be reflexive, as 17 . in the former example from Celestia or focussed on outward bodies or agen- 18 . cies such as in Darkthrone's 'Natassja in Eternal Sleep' where the narrator 19. watches his love, Natassja, burned at the stake, announcing his soul had been 20 . immolated too, but now recognizing his love is eternal. Here, the act of decay 21. has elicited a response, in that Natassja's life force will go on without her body, 22. inside him. Not so much an afterlife asthe Christian religion would believe it 23 . - but a continuation of life in a new form, such as is the case with Wolves. 24. This turns us towards Hegel's notion of digestion, followed through by Zizek, 25. in that inner potential only finding truth in external expression (Stephanou 26. 2012). Hegel's apple transforms after its dematerialization into a new form, 27. the extraction of the nutrients from within, and as Stephanou points out, the 28 . apple seeds carry life further growing out of excrement. A fitting allegory for 29 . black metal decay. 30. 31.

Decay as transgression from the self 32 .

Decay in black metal can also be used in such ways as in that found in the 33 . song 'Chainsaw: Gutsfuck' by Mayhem (lyrics reproduced above). In this song, 34. the narrator (here, 'Maniac') directs a particularly brutal murder of a female he 35. is sexually attracted to. Here the decay of the female body serves two distinct 36 . purposes - the language itself, consisting of the graphic nature, and the abun- 37. dance of expletives is the perfect example of the unrefined nature of the music 38 . of youth. In this song, the band wanted to disgust their listeners and set about 39. to perform this task. By taking the lyrics to such an extreme, one can visual- 40. ize the youthful exuberance of the band in question. A group of young men 41. clearly obsessed with slasher-type movies, trying to create the equivalent of the Texas Chainsaw Massacre in musical form, albeit it with tongue firmly set in cheek. The sexual content of the song was unashamedly violent, 'Chainsaw...' can be interpreted as both a youthful blast of sickness and a will to submit to selfish carnal desire. The woman in question is clearly not too pleased by the prospect of having intercourse, but due to black metal lawlessness inherent in the sovereign - the perpetrator will have what he wants. In essence, this also resembles Hegel's digestion in that the narrator's attraction to the subject increases with the destruction of her flesh. The corruption of the perfect form,

1.
.
.
10.
12.
13.
14.
15.
.

0.
5. 9. . . 3.

7.


1. the breaking down of tissue merely fuels desire. Hegel and Bataille's notions

2. of the individual's pursuit of death and violence manifesting in erotic pleasure

3. are both observable in this mutation.

4. Decay, as discussed, carries with it multiple layers of meaning that are 5. tailored to express the writer's particular interest. It can be seen as all-encom6. passing, as it bleeds logically into the themes of nature, eschatology and 7. atavism and can serve as a link in the chain binding such seemingly disparate 8. ideas together.

9.

10. Tonight all flags must burn in place of steeples.

11.

12.

13.

14.

15.

16.

17.

18.

19.

20.

21.

22.

23.

24.

Autonomy must return into the hands of the people.

This is war on our oppressors.

The concept of capitalism robs us of our very nature.

Destroys our tribes, torn apart our families.

Gagged and bound, we slit the throat of the henchman then laugh at the contradiction.

Falsify our inspiration, numbed by media.

The tools of complacency market our fucking rebellion.

Behold the chains of profit.

There is nothing sacred!

We are convinced that we are free because we are not starving.

But our souls starve for more than profit and convenience. ${ }^{9}$

The above lyrics by black metal artist Austin Lunn (performing as A. Lundr in Panopticon) offer the idea that the dual evils of capitalism and religion are contributors to societal decay and that fighting băckis not only possible, but herein lies a call to arms. The title itself suggests that he who burns the flag in protest will bear a torch that lights the way or the revolution. Others are less inclined to fight back and simply satisfied to make the ultimate nihilistic sentiment and watch the world burn. Some however display ideas that could be called revolutionary, whether thesedideas are well conceived or not is up to the individual that made the observation, but interestingly the juxtaposition of archaic descriptors such as souts with more modern lexicon indicates here that the answer lies in the transformation of the people following a return to the old ways before capitalism. Consequently modern life can exist without such bondage to our oppressors.

Erik Danielsson of Watain comments that:

I think we can all feel disgusted by corpses and the smell of blood and I think that is great. It hardens you and it gets you to the point where you do not give a fuck. It takes a knife and it cuts that part of your brain out and leaves it backstage because you can't take it onstage with you. ${ }^{10}$

Metallers such as Danielsson use pain and suffering in their work to create disgust, such groups still recognize the taboo nature of what they do, but operate in that sphere. This is part of their transgression, a transgression that leads to transcendence. The change that black metal forces upon the performer is deemed necessary, perhaps a must in order to survive within the black metal culture. This can be further interpreted as encouraging a state
9. Panopticon (2008).

10. Doran (2012). 
of temporary sociopathy to adapt to life in the extremes. As he explained in 1 . another interview:

I came to the point where I'm going to let the pain be not only in my band where I can perform music which I love, but it's also going to be my tool of exploring the Satanic nature of myself. It's going to be my vessel of transcendence. That changed my whole outlook. ${ }^{11}$

He speaks of using his transgression to further his own knowledge, 9. becoming ever more aware of the darker aspects of his psyche. Such explora- 10. tion is only possible with this vessel. Here we see a link made between decay 11 . and Satanism itself, a prominent feature of black metal (to varying degrees), 12. adding yet another layer to decay's relevance within the scene. 13.

As decay is such a popular topic, the potential for it to be subsumed by 14 . those who would be deemed 'posers' and regurgitated in an attempt to'sound 15 . true' is quite high. The early Mayhem song 'Chainsaw Gutsfuck' is an example 16. of a band using lyrics to that imply decaying flesh, but not particularly using 17. decay in a metaphorical, or even particularly deep, sense. In this track, it is 18. solely an attempt to 'gross out' the listener and push the envelope of what 19 . even the most hardened metalheads would accept. Instead of being deemed 20 . 'posers', Mayhem would go on to perform a vital role in the scene, this 21. example helps reaffirm a horror access 'entry point' into black metal. As they 22 . became more mature, reliance on this kind of 'slasher fiction' itself transforms 23. and reveals more maturity and complexity, comparable to the process of atro- 24 . phy itself.

\section{Alternative perspectives on decay}

Decay as a physical process can be quite divisive. When considering the system of consumption that takes over a body until it has fully returned to the earth. How black metal fans react towards physical atrophy diverge roughly parallel to their listening choices within the subculture. It appeared that black metallers who had spent their time singing the praises of nature-worshippers Wolves in the Throne Room would correspond more to a belief that decay was a necessarypart of the cycle of life and therefore part of nature's majestic beauty.

An interesting analogy offered is the comparison of the relentless drone prevalent in some black metal styles to the 'Om' or 'Aum' chant practiced by followers of Dharmic religions (Gurjar et al. 2009). The chant itself in Hinduism is said to be the first sound and has no translation, the first manifestation of God and therefore equating to the Earth's own vibrational frequency, a reflection of reality, and therefore the ultimate state of harmonic transcendence with the Earth. Considering this in terms of black metal, particularly the extremely atavistic side of the genre, bands such as Burzum and Wolves create imitations of this vibration to aid in transgressing societal bonds and achieving a higher state of being.

In Wilson's Melancology (2014), his contributors 'blacken' ecology with black metal theory. The resultant articles conceptualize a reintegration of the ideas of the flora- and fauna-worshipping Cascadian black metal style and the misanthropic, Satanic template espoused by Mayhem and Darkthrone. This blackened ecology can paint nature as a wilful powerful, oppressive force that should be respected - possibly viewing nature as a dark energy inclined 
1. to destroy the known, human world. It is surmised that in the absence of

2. humanity in which these songs exist, we are actually hearing further misan-

3. thropy, as the musicians turn away from society (Scott 2014). The closest to

4. human qualities we get are anthromorphosized creatures, which even then

5. are used metaphorically to allegorize the animalistic nature man has sepa-

6. rated from: 'As animals we gather around the womb-hole in the ground, shed

7. this flimsy skin, ignite our eyes again'. ${ }^{12}$ In this passage for instance, there is a

8. gathering in the rain of beings striving to return to the womb hole from which

9. they emerged. They wish to remove the flimsy skin of civilization and find

10. wonder in arcane knowledge.

11. The lyrics reproduced at the beginning of this article from black metal solo

12. artist Xasthur express an early question central to the theme of decay. After

13. the world has been destroyed, if death will even exist or, in less specific terms,

14. what follows from decay's completion? Here Xasthur presents a wandering,

15. ethereal presence fuelled by hate. Death may have ceased, and nothing is left

16. to kill, so life is too rendered meaningless. Xasthur's spectre suggests an incor-

17. poreal hatred that extends beyond concepts of life and death. If we assume

18. that total decay is the 'death of death' upon which the cycle of fife/death is

19. rendered inert, the conclusion is that once decay has completed (therefore

20. there is nothing left for even atrophy to feed itself on), the only remnant is the

21. spirit of hatred itself. This fits comfortably into the beliefs, and rituals of black

22. metal, where hatred is best described as a primordial force. Another view put

23. forward by the author and essayist JG Ballard surmised that we have created a

24. world that is purposefully unsustainable with the intention that it will collapse

25. and we can return to a previous existence freefrom the constraints of civilized

26. society (Boyle 2011). Kristeva argues along a similar path, arguing that the

27. abject contains similar desire to return tồprimal formlessness (Kristeva 1982).

28. So this ultimate destruction could consequently Yead to either a liberation of

29. new ideas and state of being or a wave of new creation. Black metal offers little

30. consolation here, besides extolling the virtues of a profane, irreligious society.

31. It does however, put purpose in this level of destructiveness, surpassing death

32. metal in supplying meaning to the 'fanciful violence and bloodlust of death

33. metal [which isn't] anything in itself - making it 'real' to 'hold greater purpose'

34. (Moynihan and Søderlind 2003: 32).

35. Through the 'wriggling biomass' of worms that feature as the subject of

36. Masciandaro's 'Worm Sign' (Masciandaro 2014), we see decay as a living, all-

37. consuming presence, which changes the host organism. It survives by'eating

38. the dead, or infecting living flesh', an appropriate metaphor for the black

39. metal subculture itself - with their propensity to use the appearance and char-

40. acteristics of death whether aesthetically, lyrically or musically. Through this,

41. the subculture grows as more individuals become 'infected'. As more fall to

42. this disease, black metal expands into darker corners of the world, growing

43. pocketed scenes everywhere it can find an anchor point. A minute number of

44. spores is all that is needed to introduce a new series of hosts, as the DIY atti-

45. tudes manage themselves particularly well.

46.

\section{Conclusion}

48. As this article has provided, decay and atrophy offer multiple opportunities for 49.

50.

51.

52. metaphor and importantly social commentary, within black metal. Here in this culture, atrophy helps define black metal and vice versa. The use of black metal theory highlights such thoughts, echoing the blackened nature of what lies 
beneath the purposely obfuscating soundscape. This cult of decay permeates 1 . the genre at every conceivable level, all aesthetic properties and the feel of these 2 . representations. We, under instructions from the artists pointing towards it, stare 3 . into this abyss and it stares back. Consequently, the act itself blackens us, infecting 4 . us. We reach new levels of ontological understanding with decay through black 5 . metal. It twists and manoeuvres into shapes that resemble the horror aesthetic 6 . that draws listeners into the genre, but upon our inspection adds multitudinous 7 . layers of meaning that demand attention and deciphering. Black metal through 8 . this lens becomes a more viscous body, reflecting the pulsing biomass that expo- 9 . nentially consumes dying organic matter. Decay will be a permanent feature of 10 . black metal going forward, as the process of rotting fits completely within the 11 . systems and beliefs of the subculture. As long as black metal continues to pulsate, 12 . there will be space for insight into rotting and decay, as this metaphorical group- 13 . ing accurately describes one of the driving impetuses of the subculture itself. 14

\section{REFERENCES}

Aites, A. and Ewell, A. (2009), Until the Light Takes (1s, USA:Variance Films.

Arnett, J. J. (1996), Metal Heads: Heavy MetalMusic and Adolescent Alienation, Colorado: Westview Press.

Boyle, F. (2011), Work! Consume! Die!, London. HarperCollins.

Burzum (1992), 'Feeble Screams fromsorests Unknown', Burzum, Norway: Deathlike Silence Productions.

Celestia (2008), 'The Seeds of Negation', Frigidiia, Apothoesia: Abstinentcia, France: Drakkar Productions.

Darkthrone (1993), 'Natassja in EternarSleep', Under a Funeral Moon, Norway: Peaceville Records.

Doran, J. (2012), 'Sympathy for the Devil', Metal Hammer, 234, London: Future Publishing, pp. 41-45.

Ekeroth, D. (2008), Swedish Death Metal, New York: Bazillion Points.

Fauna (2006), 'Rain', Rain USÄ: self-released. - (2007), Rain', Rain, USA: self-released.

Fox, D. (2009), Cold World: The Aesthetics of Dejection and the Politics of Militant Dysphoria Ropley: Zero Books.

Gurjar/A A., Ladhake S. A. and Thakare A. P. (2009), 'Analysis of acoustic "Om" chant to study its effect on the nervous system', IJCNCS International Journal of Computer Science and Network Security, 9:1, pp. 363-67.

Harris, K. D. (2000), “'Roots"?: The relationship between the global and the local within the Extreme Metal scene', Popular Music, 19, 10.1017/ S0261143000000052. (2007), Extreme Metal: Music and Culture on the Edge, Oxford: Berg.

Kelly, K. (2012), 'Ravishing Grimness', Terrorizer, \#226, p. 14.

Kristeva, J. (1982), The Powers of Horror: An Essay on Abjection, New York: Columbia University Press.

Kristiansen, J. (2011), Metalion: The Slayer Mag Diaries, New York: Bazillion Points.

Masciandaro, N. (2010), 'Introduction', Hideous Gnosis: Black Metal Theory Symposium 1, New York: Createspace.

- (2014), 'WormSign', in S. Wilson (ed.), Melancology: Black Metal Theory and Ecology, Alresford: Zero Books. 
1. Mayhem (1987), 'Chainsaw Gutsfuck', Deathcrush, Norway: Deathlike Silence

2. Productions.

3. (1995), Dawn of the Black Hearts, Colombia: Warmaster Records.

4. McGuirck, J. (2014), 'The context of phenomenological inquiry in Husserl

5. and Heidegger', Phenomenology of Intersubjectivity and Values in Husserl,

6. Cambridge: Cambridge Scholars Publishing.

7. Moynihan, M. and Søderlind, D. (2003), Lords of Chaos: The Bloody Rise of the

8. Satanic Metal Underground, 2nd ed., Washington, DC: Feral House.

9. Negarastani, R. (2010), 'Undercover softness: An introduction to the archi-

10. tecture and politics of decay', Collapse VI: Geo/Philosophy, Falmouth:

11. Urbanomic.

12. Panopticon (2008), 'Flag Burner, Torch Bearer', Panopticon, USA: Lundr Records.

13. Richardson, N. (2012), 'Looking black', Black Metal: Beyond the Darkness,

14. London: Black Dog Publishing.

15. Russo, J. (2010), 'Perpetue Putesco-Perpetually I Putrefy', Hideous Gnosis: Black

16. Metal Theory Symposium 1, New York: Createspace, pp. 93-104.

17. Scott, N. (2014), 'Blackening the green', Melancology: Black Metal E Ecology, 18. Washington: Zero Books.

19. Shakespeare, S. (2012), 'Of plications, a short summa on the nature of casca-

20. dian black metal', in N. Masciandaro and R. Negarestani (eds), Glossator 6:

21. Practice and Theory of The Commentary-Black Metal, New York: Createspace.

22. Steel for Brains (2013), 'Black salvation: A conversation with Watain', Steel for

23. Brains, http://www.steelforbrains.com/post/58236441532/watain. Accessed

24. 12 December 2017.

25. Stephanou, A. (2012), 'Black metal and the mouth: Always serving you as a

26. meal, or infected orality, pestilential wounds and scars', in N. Masciandaro

27. and R. Negarestani (eds), Glossator 6: Practice and Theory of The Commentary-

28. Black Metal, New York: Createspace

29. Thacker, E. (2014), 'Sound of the abyss', Melancology: Black Metal Theory and

30.

31.

43.

44.

45.

\section{SUGGESTED CITATION}

Hoffin, K. (2018), 'Decay as a black metal symbol', Metal Music Studies, 4:1, pp. 00-00, doi: 10.1386/mms.4.1.0_1

\section{CONTRIBUTOR DETAILS}

Kevin Hoffin is a criminologist, currently lecturing at Birmingham City University. He has research interests in subcultures, youth crime, criminal justice, policing and has a lifelong love of metal music, particularly black metal. He spends his free time reading from an ever-growing collection of comics or listening to obscure black metal. 
Contact: School of Social Sciences, Birmingham City University, The Curzon 1. Building, 4 Cardigan Street, Birmingham B4 7BD, United Kingdom. 2. E-mail: Kevin.hoffin@live.co.uk

Kevin Hoffin has asserted his right under the Copyright Desions and Patents 5. Act, 1988, to be identified as the author of this work in the format that was 6 . submitted to Intellect Ltd. 